\title{
Comparative Analysis for Aspirated and Unaspirated Consonants' Combination Ability of Commonly-used Chinese Characters
}

\author{
Jin Yasheng \\ Key Lab of China's National Linguistic Information \\ Technology,Northwest University for Nationalities \\ Lanzhou,China \\ E-mail: jys2011Y@163.com
}

\author{
Xie Linqing \\ Key Lab of China's National Linguistic Information \\ Technology,Northwest University for Nationalities \\ Lanzhou,China \\ E-mail: xieling8826@sohu.com
}

\begin{abstract}
This paper uses the theories of phonemics, phonology and mathematical statistics to concrete compare and analysis the combination ability of 12 aspirated and unaspirated consonants in 2500 commonly-used standard Chinese characters' Initial system. Through the research some resulted have gained that: 1)the frequency distribution of aspirated and unaspirated consonants has correlation with the number of homophone in 2500 commonly-used standard Chinese characters; 2)aspirated and unaspirated consonants has consistent with the corresponding relation when they combine with different structure types finals; 3)the combination ability of the unaspirated sound is stronger than aspirated sound of The same method of articulation and pronunciation; 4) the combination of aspirated sound and nasal finals is common in commonly-used Chinese characters system. This paper provides data and certain reference value for the further study on phonological system of standard Chinese.
\end{abstract}

Keywords- aspirated sound; unaspirated sound; combination ability

\section{INTRODUCTION}

Chinese commonly used 2500 words is not only the basis of the use of Chinese, but also the most can represent and react the system of Chinese phonological structure, to analysis and research on language from the point of view of phonemics is a practical and effective way of language research[1].In the past, the research of phoneme theory tends to focus on the phonemic opposition analysis, phonetic teaching of the difference of the different phoneme pronunciation and based on the phoneme system acoustic research and so on. But from the theory of phonemes to research enclosed Spaces the specific phonemes description and comparison of aspirate and unaspirated sound in mandarin commonly used 2500 a consonant system will be relatively less, and through the phonology, phonemics and statistics into the method of combining to statistical analysis the combination ability of a specific phoneme in a specific language in different levels is more rare. Aspirate and unaspirated sound as a set of correspondence in order and difference in characteristics apparently initials of Chinese initials system[2]. It can clearly reflect regulation characteristics of the collocation and combination ability of distinctive features of opposition phoneme in Chinese initials system.This paper based on the theories of phonology, phonetics and statistical, and the method of structural linguistics to study and analysis the distribution, collocation relations and the combination ability difference of aspirate and unaspirated sound in Initials phoneme system of Chinese commonly used 2500 words, then provides reference data and theoretical basis for the further study of Chinese phonological system in the future.

\section{RESEARCH METHODS}

This paper based on Chinese language work committee established by a large number of balance corpus of 2500 adverted consonant as library, and use the theory of structural linguistics, to hierarchical analysis the language, thus aspirate and unaspirated sound in Chinese commonly used 2500 words initials system phoneme structure for different structure collocation levels of analysis and comparative study, the syllable in metathesis, and use SPSS software and statistical methods to statistics and analysis plenum phoneme and unaspirated phonemic combination collocation capacity hierarchically.

\section{THE DISTRIBUTION ANALYSIS AND COMPARISON OF ASPIRATE AND UNASPIRATED SOUNDS}

According to the data of Statistical frequency of aspirate and unaspirated sound in the Chinese commonly used 2500 words' syllable initial system we can get aspirate and unaspirated sound frequency pattern; Based on statistics and quantitative the frequency of aspirate and unaspirated sound in both initials system of affirming Chinese syllables and Mandarin 400 syllable combination, we can gain a quantitative frequency comparison chart both of the above. Figure 1 and figure 2.

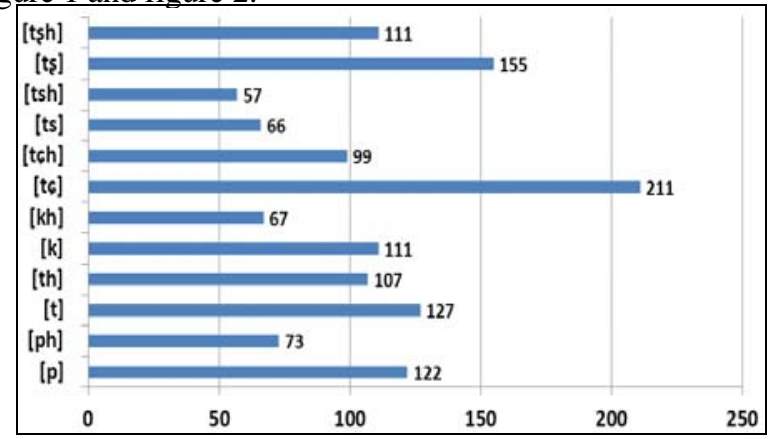

Figure 1. aspirate and unaspirated sound frequency distribution diagram 


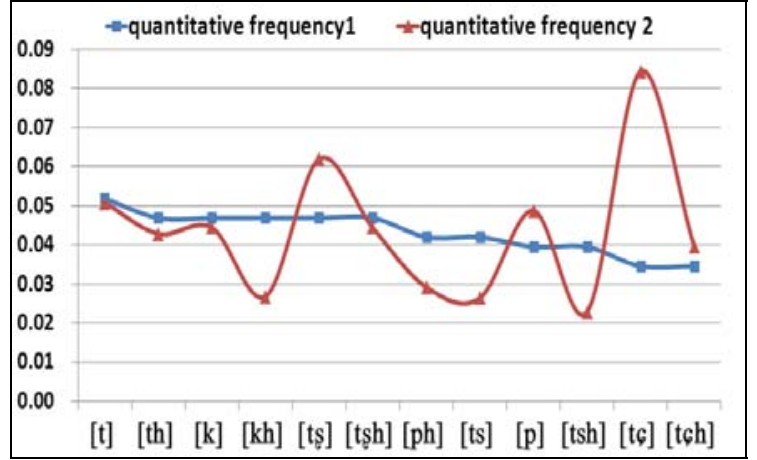

Figure 2. quantitative frequency chart

In figure 1, abscissa represents the quantity of frequency of aspirate and unaspirated sounds, ordinate represents the specific aspirate and unaspirated sounds. In figure 2, abscissa represents the specific aspirate and unaspirated sound, ordinate represents the quantification of frequency value, quantitative frequency 1 and 2 respectively represents quantitative frequency of aspirate and unaspirated sound in the initials system of mandarin four hundred syllables and affirming Chinese syllables. According to the figure 1 and figure 2 can see:

In the frequency distribution of aspirate and unaspirated sound of affirming Chinese, the same method of articulation and pronunciation unaspirated sound in the quantity of frequency distribution significantly higher than the corresponding aspirate frequency. Thus it can be seen in the frequency quantity and combination ability unaspirated sound than aspirate;The front of the tongue clear plug wipe unaspirated sound [tc] represents the highest frequency , than the corresponding aspirate [tch] frequency high to more than half.

In the quantitative frequency comparison chart aspirate and unaspirated sound of affirming Chinese and mandarin 400 syllables, quantitative frequency distribution of aspirate and unaspirated sound in mandarin 400 syllables of is very equilibrium concentration, but compared with it, the quantitative frequency of aspirate and unaspirated sound in affirming Chinese have larger fluctuation change. The biggest change is [t6] of Chinese affirming high to 0.05 than it in mandarin 400 syllables, in the next place is [kh] and [tsh].

Thus it can be seen, the quantitative frequency of aspirate and unaspirated sound in mandarin 400 syllables is less volatile aspirate and unaspirated sound, quantitative frequency of aspirate and unaspirated sound in Chinese commonly used 2500 words is suddenly increase, frequency of utilization is high, corresponding is in affirming Chinese system, and homophone quantity will become more when the combination syllabic appear. Otherwise, vice versa.

\section{THE RELATIONSHIP BETWEEN ASPIRATE/UNASPIRATED SOUND AND FINALS PRONUNCIATION MOUTH CLASSIFICATION}

According to the place of articulation and pronunciation methods consonant can be divided into different types, according to mouth shapes when pronouncing the start vowels, they may be divided into open-mouths, even-teeth, close-mouths, and pursed -mouths. Through the statistical data of collocation relations and collocation frequency distribution situation of aspirate / unaspirated sound with finals pronunciation mouth classification, to study combination ability of aspirate and unaspirated sound in the initial system of Chinese commonly used 2500 words.

\section{A. The Collocation Relations of Aspirate/Unaspirated} Sound and Finals Pronunciation Mouth Classification

According to the statistics collocation relations of 12 aspirate/unaspirated sounds in Chinese commonly used 2500 words initial system and finals pronunciation mouth classification, to reveal collocation situation of aspirate/ unaspirated sound and finals pronunciation mouth classification, see table I.

TABLE I. THE TABLE OF THE COLLOCATION RELATIONS OF ASPIRATE/UNASPIRATED SOUNDS AND FINALS PRONUNCIATION MOUTH CLASSIFICATION

\begin{tabular}{|c|c|c|c|c|}
\hline \multirow{2}{*}{$\begin{array}{c}\text { final } \\
\text { Asp/ unasp }\end{array}$} & \multicolumn{4}{|c|}{ finals pronunciation mouth classification } \\
\cline { 2 - 5 } & open-mouths & even-teeth & close-mouths & pursed-mouths \\
\hline$[\mathrm{p}][\mathrm{ph}]$ & + & + & + & - \\
\hline$[\mathrm{t}][\mathrm{th}]$ & + & + & + & - \\
\hline$[\mathrm{t} 6][\mathrm{tch}]$ & - & + & - & + \\
\hline$[\mathrm{k}][\mathrm{kh}]$ & + & - & + & - \\
\hline$[\mathrm{ts}][\mathrm{tsh}]$ & + & - & + & - \\
\hline$[\mathrm{ts}][\mathrm{tsh}]$ & + & - & + & - \\
\hline
\end{tabular}

According to the above can be seen:

In the collocation of finals pronunciation mouth classification and unaspirated sound, only [p],[t] can collocate open-mouths, even-teeth and close-mouths, [k], [ts], [ts] only can collocate open-mouths and close-mouths; only [t6] can match even-teeth and pursed -mouths, but not with open-mouths and close-mouths.

In the collocation of finals pronunciation mouth classification and aspirate, [ph] and [th] can match openmouths even-teeth and close-mouths, but [kh] , [tsh] and [tsh] only can match open-mouths and close-mouths. [tch] is special, it only can match even-teeth and pursed -mouths.

Overall, collocation relations between the same method of articulation and pronunciation of aspirate and unaspirated sound and finals pronunciation mouth classification have almost the same correspondence. Aspirate and unaspirated sound of bilabial vioceless plosive, blade-alveolar vioceless plosive only can match open-mouths, even-teeth, closemouths;blade-alveolar vioceless affricate, blade-palatal vioceless affricate and voiceless velar affricate only can match open-mouths and close-mouths;Palatal vioceless affricate only can match even-teeth and pursed -mouths. The combination ability of all aspirated and unaspirated sound with open-mouths and close-mouths is the strongest,but the combination ability of all aspirated and unaspirated sound with pursed -mouths is the weakest. 
B. The Collocation Distribution of Aspirate/Unaspirated Sound and Finals Pronunciation Mouth classificatio

According to the Collocation relations of aspirated/unaspirated sound in Chinese commonly used 2500 words initial system and finals pronunciation mouth classification, and statistics collocation frequency of them, then get the frequency distribution of aspirate and unaspirated sound the match in the finals pronunciation mouth classification, see figure 3 and figure 4 .

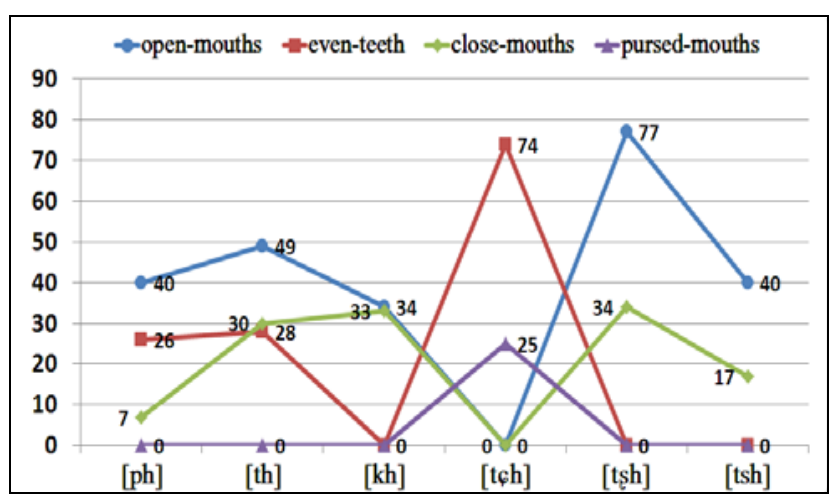

Figure 3. the distribution of aspirates match the finals pronunciation mouth classification.

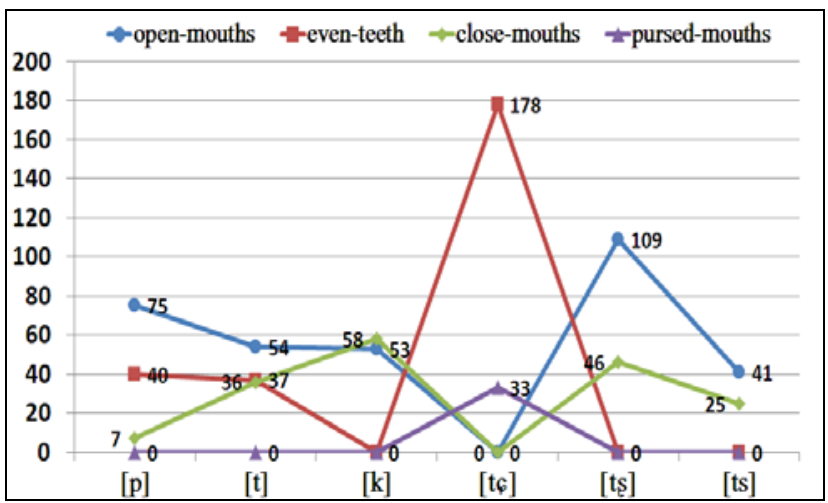

Figure 4. the distribution of unaspirated sounds match the finals pronunciation mouth classification

The abscissa of figure 3 and figure 4 represents the aspirate and unaspirated sound in Chinese commonly used 2500 words initial system, the ordinate represents the specific quantity of the collocation of aspirate and unaspirated sound with the finals pronunciation mouth classification in Initials and finals system of Chinese commonly used 2500 words.From the chart we can see:

All the value is 0 when aspirate initials collocate with pursed-mouths in the aspirate, except [tch], that is to say almost all aspirate initials don't collocate with pursed mouths.In addition, [kh] and [tsh] don't collocate with eventeeth, [tch] only can collocate with even-teeth and pursed mouths, the frequency of [tsh] collocate with open-mouths is the highest, except [tch], the rest of aspirate can't collocate with pursed-mouths.

In unaspirated sound, in addition to [t6], the distribution value is 0 when the rest 5 unaspirated sounds collocate with pursed -mouths. The number of finals of [t6] collocate with distribute in even-teeth is the most, and they can't collocate with open-mouths and close-mouths. [kh],[tsh] can't collocate with even-teeth. All the unaspirated sounds can't collocate with open-mouths, even-teeth, close-mouths, and pursed-mouths completely.

According to the data through distribution of aspirate and unaspirated sounds collocate with the finals of open-mouths, even-teeth, close-mouths, and pursed-mouths, we can gain that the combination ability of corresponding aspirate / unaspirated sounds and finals of open-mouths, even-teeth, close-mouths, and pursed-mouths almost unanimously. The quantity of finals that unaspirated sounds collocate with is higher than the quantity of finals that corresponding aspirates collocate with. Thus it can be seen, in the same method of articulation and pronunciation, the combination ability of unaspirated sound is higher than aspirates.

\section{THE RELATIONSHIP BETWEEN ASPIRATE / UNASPIRATED SOUNDS AND FINALS STRUCTURE TYPE}

According to the respective structure, finals can be divided into different final structure types, namely simple vowels, diphthong and nasal finals. To statistics and classified summary results of the final structure types that the aspirate and unaspirated sounds collocate with in Chinese commonly used 2500 words initial system, then get the specific frequency in their collocations, and calculated the weight distribution, see table II and table III.

TABLE II. THE WEIGHT OF THE COLLOCATION OF ASPIRATES WITH DIFFERENT FINAL STRUCTURE TYPES

\begin{tabular}{|c|c|c|c|}
\hline \multirow{2}{*}{$\begin{array}{c}\text { finals } \\
\text { aspirates }\end{array}$} & \multicolumn{3}{|c|}{ finals structures type } \\
\cline { 2 - 4 } & simple vowels & diphthong & nasal finals \\
\hline [ph] & $0.96 \%$ & $0.76 \%$ & $1.20 \%$ \\
\hline$[\mathrm{th}]$ & $1.04 \%$ & $1.32 \%$ & $1.92 \%$ \\
\hline$[\mathrm{kh}]$ & $0.72 \%$ & $0.84 \%$ & $1.12 \%$ \\
\hline$[\mathrm{tch}]$ & $1.24 \%$ & $0.92 \%$ & $1.80 \%$ \\
\hline$[\mathrm{tsh}]$ & $1.36 \%$ & $0.88 \%$ & $2.20 \%$ \\
\hline$[\mathrm{tsh}]$ & $0.64 \%$ & $0.76 \%$ & $0.88 \%$ \\
\hline
\end{tabular}


TABLE III. THE WEIGHT OF THE COLLOCATION OF UNASPIRATED SOUND WITH DIFFERENT FINAL STRUCTURE TYPES

\begin{tabular}{|c|c|c|c|}
\hline \multirow{2}{*}{$\begin{array}{c}\text { finals } \\
\text { unaspirates }\end{array}$} & \multicolumn{3}{|c|}{ finals structures type } \\
\cline { 2 - 4 } & simple vowels & diphthong & nasal finals \\
\hline$[\mathrm{p}]$ & $2 \%$ & $1.24 \%$ & $1.64 \%$ \\
\hline$[\mathrm{t}]$ & $1.20 \%$ & $1.80 \%$ & $2.08 \%$ \\
\hline$[\mathrm{k}]$ & $1 \%$ & $1.56 \%$ & $1.88 \%$ \\
\hline$[\mathrm{t}]$ & $2.20 \%$ & $2.72 \%$ & $3.52 \%$ \\
\hline$[\mathrm{ts}]$ & $2.76 \%$ & $1.12 \%$ & $2.32 \%$ \\
\hline$[\mathrm{ts}]$ & $0.72 \%$ & $1.20 \%$ & $0.72 \%$ \\
\hline
\end{tabular}

According to the weight distribution of the collocation of aspirated sound with final structure type, the highest weight combination is aspirated blade-palatal vioceless affricate [tşh] with nasal finals, well the lowest weight combination is aspirated blade - alveolar vioceless affricate [tsh] with simple vowels. And the sum of collocation of [tsh] with 3 final structure types are less than other aspirate with different structure of the final match. The collocation weight of all aspirate with nasal finals are maximum, compared with the collocation weight of aspirate with other structure type finals, thus it can be seen the combination ability of aspirate with nasal final is the strongest.

According to the perspective of the collocation of unaspirated sound and final structure, the highest collocation rate is the collocation of palatal unaspirated vioceless affricate[tc] with nasal finals, and at the lowest rate are the collocation of unaspirated voiceless blade-alveolar affricate [ts] with simple vowels or nasal finals. The collocation rate of $[\mathrm{t}],[\mathrm{k}],[\mathrm{t} 6]$ with nasal finals is high, compared with the collocation rate of them with other final structure types is the highest, the ratio of the sum weight of the collocation of unaspirated sound with 3 final structure types is 5:5:6.

So in general, the collocation of aspirate / unaspirated sounds with final structure types has the very strong similarity, and, in general, the collocation sum weight of aspirate and unaspirated with nasal final beyond they collocated with other final structure types. The collocation weight of the aspirate and unaspirated sounds of the same method of articulation and pronunciation have the corresponding relation, the collocation of part unaspirated sounds and all the aspirates with nasal finals are higher than they collocate with other finals structure type.

\section{CONCLUDING REMARKS}

This paper based on the library of Chinese commonly used 2500 words ,to study aspirate and unaspirated sounds that correspondence in order in the initials system of Chinese commonly used 2500 words, to statistics analysis and compare the frequency distribution and combination ability of aspirate and unaspirated sounds. At the same time, based on theories of phonemics, phonology and mathematical statistics ,to compare and study the frequency distribution ,the collocation with finals pronunciation mouth classification and final structure types of aspirate and unaspirated sound, then found the proportionality of aspirate frequency distribution is stronger than unaspirated sound in the initials system of Chinese commonly used 2500 words; Aspirate no matter collocate with different structure types of the finals on collocation, or collocate with finals pronunciation mouth classification, almost have the same corresponding relations; The combination ability of aspirated is obviously stronger than the corresponding unaspirated sound of the same place of articulation and pronunciation methods. The research of this paper basically reflects collocation distribution pattern of aspirate and unaspirated sound in the system of Chinese commonly used 2500 words, and provides data and certain reference value for the further study on phonological system of standard Chinese.

\section{REFERENCES}

[1] Dinoj Surendran,Analysis and Automatic Recognition of Tones in Mandarin Chinese,2007. pp.100-110.

[2] Greenberg,H.H. A method of measuring functional yield as applied to tone in Mrican languages. Georgetown University Monograph Series on Languages and Linguistics Dec.1959. pp.7-16

[3] Hockett,C.F. A Manual of Phonology. Baltimore Waverly Press,1955. pp.218-220.

[4] Li Yonghong ,Fang Huaping, “Chinese pinyin international phonetic alphabet conversion rules and implementation” [C]. 2012 future information technology and management science and engineering international academic conference proceedings. 2012.4, pp.3-4.

[5] Li Yanrui, "Mandarin phonology research" [J]. Chinese, 1984 pp.3740

[6] Huang Borong,Liao Xudong, “modern Chinese” [M]. Higher education press 2002, pp.20-100.

[7] Wang Lijia,"the Chinese phonetic alphabet with the theory of phonology and phonetic teaching" [J]. Journal of language application

[8] Wang Lijia, "the phonology foundation” [M]. Beijing: Chinese press, vol.2, pp.30-45.

[9] Cen Qixiang, "Study linguistics brief rundown” [M]: Beijing publishing house, vol.2, pp.10-20.

[10] Liu Runqing, Feng Zongxin."Linguistics theory and genre” [M] Nanjing Normal University press, vol.2, 2002, pp.30-100. 